\title{
Erratum to: Hepatitis viruses in Ethiopia: a systematic review and meta-analysis
}

\author{
Yeshambel Belyhun ${ }^{1,2^{*}}$, Melanie Maier ${ }^{1}$, Andargachew Mulu ${ }^{1,2}$, Ermias Diro ${ }^{3}$ and Uwe Gerd Liebert ${ }^{1}$
}

\section{Erratum}

After the publication of this work [1] it was noticed that the citation lists on figures 3 and 4 were incorrect. The original version of this article was corrected.

The citation list on figure 3 was put as:

$[9,10,13,16,17,25-27,29-35,38,39,42,43,53,54$, $57,59,62-65,67,85,87-90,92,93,95-97]$

It should have been:

$[85,59,91,89,29,87,25,87,26,90,92,93,54,16,88$, $95,96,27,9,35,38,39,57,42,97,17,31,33,32,62,30$, $10,34,63,13,43,42,62,64,67,53,65]$

The citation list on figure 4 was put as:

[9-12, 28, 32, 39, 49, 53-58, 64, 66-68, 98, 99]

It should have been:

$[56,54,49,55,57,28,9,39,68,58,58,11,66,12,66$,

$11,12,53,64,10,67,32,98,99]$

The publisher apologises for these errors.

\begin{abstract}
Author details
'Institute of Virology, Faculty of Medicine, Leipzig University, Leipzig, Germany. ${ }^{2}$ School of Biomedical and Laboratory Sciences, College of Medicine and Health Sciences, University of Gondar, Gondar, Ethiopia.

${ }^{3}$ Department of Internal Medicine, College of Medicine and Health Sciences, University of Gondar, Gondar, Ethiopia.
\end{abstract}

Received: 3 January 2017 Accepted: 3 January 2017

Published online: 01 February 2017

\section{Reference}

1. Belyhun Y, Maier M, Mulu A, Diro E, Liebert UG. Hepatitis viruses in Ethiopia: a systematic review and meta-analysis. BMC Infect Dis. 2016;16:761.

\footnotetext{
* Correspondence: belyhun@gmail.com

${ }^{1}$ Institute of Virology, Faculty of Medicine, Leipzig University, Leipzig, Germany

${ }^{2}$ School of Biomedical and Laboratory Sciences, College of Medicine and Health Sciences, University of Gondar, Gondar, Ethiopia

Full list of author information is available at the end of the article
} 